\title{
COMPETÊNCIAS E FUNÇÕES DOS TUTORES ONLINE EM EDUCAÇÃO A DISTÂNCIA
}

\author{
JOÃO MATTAR ${ }^{1}$ \\ ORCID: https://orcid.org/0000-0001-6265-6150 \\ LUCILENE MARQUES MARTINS RODRIGUES ${ }^{2}$ \\ ORCID: https://orcid.org/0000-0003-1609-4761 \\ WANDERLUCY CZESZAK ${ }^{3}$ \\ ORCID: https://orcid.org/0000-0002-9434-655X \\ JULIANA GRACIANI ${ }^{4}$ \\ ORCID: https://orcid.org/0000-0002-3055-3381
}

\begin{abstract}
RESUMO: Este artigo estuda as competências e funções dos tutores online em educação a distância (EaD). Envolve uma revisão sistemática de literatura em língua portuguesa e a elaboração de um modelo teórico para orientar a formação de tutores. Os textos selecionados na revisão são analisados qualitativamente por um processo de codificação e categorização com o suporte do software MAXQDA. Códigos baseados na literatura são inicialmente propostos, mas outros são incluídos durante a análise. $\mathrm{O}$ modelo apresentado como resultado da pesquisa levou em consideração a frequência da ocorrência das categorias nos textos. Dentre as competências dos tutores online, destacam-se: gerenciais, saberes disciplinares, saberes pedagógicos, habilidade de comunicação, competências socioafetivas e habilidades tecnológicas. As funções básicas do tutor online em EaD, identificadas na pesquisa, são: gerenciais, pedagógicas e sociais. O modelo proposto procura relacionar as competências com essas funções. Deve servir, nesse sentido, para orientar a formação de tutores, contrapondo-se à tendência de precarização do trabalho docente online.
\end{abstract}

Palavras-chave: Tutoria; Educação a Distância; Competências; Revisão de Literatura; Brasil.

\section{COMPETENCIES AND FUNCTIONS OF ONLINE TUTORS IN DISTANCE EDUCATION}

\begin{abstract}
This article explores the competences and functions of online tutors in distance education (DE). It involves a literature review and the elaboration of a theoretical model to guide the training of tutors. The texts selected in the review are analyzed qualitatively by a coding and categorization process supported by MAXQDA. Literature-based codes are initially proposed, but others are included during the analysis. The model presented considered the frequency of occurrence of categories in the texts. Among the competences of online tutors, the following stand out: managerial, disciplinary knowledge,

\footnotetext{
${ }^{1}$ Pontifícia Universidade Católica de São Paulo (PUC-SP). São Paulo, SP, Brasil. < joaomattar@gmail.com>

${ }^{2}$ Centro Universitário Internacional Uninter. FAE Centro Universitário. Curitiba, PR, Brasil.

$<$ lucilenemmrodrigues@gmail.com>

${ }^{3}$ Faculdade Finaci. São Paulo, SP, Brasil.<wanderlucyc@gmail.com>
}

${ }^{4}$ Centro Universitário FMU. Faculdades Metropolitanas Unidas. São Paulo, SP, Brasil. <graciani2050@gmail.com>
\end{abstract}


pedagogical knowledge, communication skills, socio-affective skills and technological skills. The basic functions of the online tutor in DE, identified in the research, are: management, pedagogy and social. The proposed model seeks to relate these competencies to these functions. It should serve, in this sense, to guide the training of tutors, in opposition to the tendency of precariousness of online teaching work.

Keywords: Tutoring; Distance Education; Competencies; Literature review; Brazil.

\section{HABILIDADES Y FUNCIONES DE TUTORES EN LÍNEA EN EDUCACIÓN A DISTANCIA}

RESÚMEN: Este artículo estudia las habilidades y funciones de los tutores en línea en educación a distancia (ED). Implica una revisión sistemática de la literatura en portugués y el desarrollo de un modelo teórico para guiar la formación de tutores. Los textos seleccionados en la revisión se analizan cualitativamente mediante un proceso de codificación y categorización con el apoyo del software MAXQDA. Inicialmente se proponen códigos basados en literatura, pero se incluyen otros durante el análisis. El modelo presentado como resultado de la investigación tuvo en cuenta la frecuencia de aparición de las categorías en los textos. Entre las habilidades de los tutores en línea, se destacan las siguientes: gestión, conocimiento disciplinario, conocimiento pedagógico, habilidades de comunicación, habilidades socioafectivas y habilidades tecnológicas. Las funciones básicas del tutor en línea en ED, identificadas en la investigación, son: gestión, pedagógica y social. El modelo propuesto busca relacionar estas competencias con estas funciones. En este sentido, debería servir para guiar la formación de tutores, contrarrestando la tendencia de precariedad del trabajo de enseñanza en línea.

Palabras clave: Tutoría; Educación a distancia; Habilidades; Revisión de literatura; Brasil. 


\section{INTRODUÇÃO}

$\mathrm{Na}$ educação a distância $(\mathrm{EaD})$ no Brasil, atuam basicamente dois tipos de tutores: os tutores presenciais, que trabalham nos polos de apoio presencial, e os tutores a distância (ou online), que trabalham nos ambientes virtuais de aprendizagem (AVA). Apesar de vários problemas enfrentados para o exercício do seu trabalho, que abordaremos neste texto, esses profissionais introduzem um componente humano em um ambiente dominado pelas tecnologias e marcado pela padronização, mecanização e rigidez.

Este artigo procura responder fundamentalmente a duas questões: (1) quais são as principais competências necessárias para o trabalho do tutor online em educação a distância e (2) quais são as principais funções que o tutor online desempenha na educação a distância? A partir de uma revisão sistemática da literatura em língua portuguesa, é proposto um modelo teórico que apresenta e relaciona essas competências e funções, cujo objetivo é contribuir com as políticas de formação de tutores. A pesquisa se justifica pela importância que a educação a distância assumiu, não apenas no Brasil, e o papel essencial desempenhado pelo tutor no processo de ensino e aprendizagem.

Para Perrenoud (2000), as competências designariam a capacidade de mobilizar, integrar e orquestrar recursos como conhecimentos, habilidades e atitudes para lidar com situações. Aretio (2002), por exemplo, diferencia quatro competências socioafetivas necessárias aos tutores: cordialidade, capacidade de aceitação, honradez e empatia. Palloff e Pratt (2002, 2004), por sua vez, distinguem as competências técnicas (domínio de ferramentas e tecnologias) das competências gerenciais (elaborar regras e tomar decisões a respeito do ritmo dos cursos). De outro lado, Moore e Kearsley (2007) diferenciam quatro funções desempenhadas pelos tutores: ensino, acompanhamento do progresso do aluno, apoio ao aluno e contribuições para o aperfeiçoamento geral do sistema.

A próxima seção descreve a metodologia utilizada nesta pesquisa. A terceira seção apresenta e analisa os resultados. A quarta seção discute esses resultados e propõe um quadro teórico que relaciona as principais competências e funções dos tutores online identificadas pela pesquisa. Por fim, a conclusão apresenta resultados relacionados à precarização do trabalho do tutor online e aponta para trabalhos futuros em relação a políticas para sua formação.

\section{METODOLOGIA}

Foi realizada uma revisão sistemática de literatura em língua portuguesa seguindo as orientações propostas por Okoli (2015). O Google Acadêmico foi utilizado como base para a pesquisa. Uma busca foi realizada no primeiro semestre de 2017 com a seguinte expressão, excluindo patentes e citações:

tudonotítulo: (tutor OR tutoria OR tutores) competências OR competência OR saber OR saberes OR função OR funções

Essa busca inicial resultou em 93 textos, dos quais foram lidos os títulos e os resumos e, quando necessário, os textos completos, mas de maneira apenas exploratória. Utilizaram-se os seguintes critérios de inclusão, para definir quais textos seriam selecionados para leitura na íntegra:

a) artigos publicados em periódicos, trabalhos apresentados em eventos acadêmicos, dissertações de mestrado, teses de doutorado, capítulos ou livros;

b) textos em que o tutor atuava em cursos superiores de graduação;

c) textos que tratavam do tutor online;

d) textos que estavam baseados em algum tipo de coleta de dados empírica para identificar saberes, competências e/ou funções dos tutores;

e) textos escritos em língua portuguesa.

Além disso, foram excluídos, a princípio, textos que exploravam competências e funções dos tutores em cursos específicos, privilegiando-se, assim, as pesquisas que exploravam as funções genéricas do tutor a distância. Foram ainda consultadas outras publicações dos mesmos autores dos textos que haviam sido inicialmente selecionados, mas que não tinham aparecido na busca inicial.

Após a triagem inicial, restaram 34 textos, que foram importados para um projeto no software de análise qualitativa MAXQDA, versão Analytics Pro. Uma estrutura inicial de codificação com quatro níveis, descrita a seguir, foi elaborada com base na literatura. O trabalho de codificação dos 
textos foi conduzido seguindo as orientações de Saldaña (2016), para quem a codificação qualitativa conseguiria capturar a essência dos dados em função de similaridades, regularidades e padrões, facilitando assim o desenvolvimento de categorias e, por consequência, da análise de suas conexões. A análise qualitativa, portanto, se desenvolveria de códigos em direção a categorias, relações, proposições, temas e conceitos, para construir teorias.

Os códigos iniciais para as competências dos tutores basearam-se nas categorias propostas por Tecchio et al (2010), que as dividiram em técnicas (conhecimentos e habilidades) e comportamentais (atitudes), conforme o Quadro 1.

Quadro 1 - Perfil de competências do cargo de tutor

\begin{tabular}{|l|l|}
\hline $\begin{array}{l}\text { Competências Técnicas (conhecimentos e } \\
\text { habilidades) }\end{array}$ & Competências Comportamentais (atitudes) \\
\hline Conhecimento das rotinas de trabalho & Organização e Planejamento \\
\hline $\begin{array}{l}\text { Conhecimento em informática básica/ambiente } \\
\text { virtual de ensino-aprendizagem }\end{array}$ & Pró-atividade \\
\hline Conhecimento pleno da disciplina ministrada & Automotivação \\
\hline $\begin{array}{l}\text { Conhecimento sobre educação a distância/sobre o } \\
\text { curso }\end{array}$ & Capacidade de síntese e análise \\
\hline Relacionamentos interpessoais & Empatia \\
\hline Comunicação (oral/escrita) & Equilíbrio emocional \\
\hline Trabalho em equipe & Flexibilidade \\
\hline & Comprometimento e Assiduidade \\
\hline & Liderança \\
\hline & Criatividade \\
\hline
\end{tabular}

Fonte: Tecchio et al (2010).

Por sua vez, Bonk e Dennen (2003) indicam que o tutor desempenha diferentes papéis ou funções, como: administrativas, pedagógicas, sociais e tecnológicas.

Em primeiro lugar, organiza a classe virtual, definindo o calendário e os objetivos do curso, dividindo a turma em grupos e deixando claras as expectativas em relação aos alunos e ao nível de interação esperada. A função do tutor seria também de acompanhar a aprendizagem dos alunos e coordenar o acesso ao material e a realização de atividades. Nesse sentido, o tutor desempenharia um papel administrativo e organizacional.

O tutor desempenha também um papel pedagógico e intelectual, que envolve elaborar atividades, incentivar a pesquisa, fazer perguntas, avaliar respostas, relacionar comentários, coordenar discussões, sintetizar seus pontos principais e desenvolver o clima intelectual geral do curso, encorajando, assim, a construção do conhecimento.

Mas o tutor desempenha também um papel social, sendo responsável por diversas atividades, tais como: contato inicial com a turma, provocar a apresentação dos alunos, enviar mensagens de agradecimento, oferecer feedback rápido aos alunos e manter um tom amigável. Nesse papel, é responsável por construir um senso de comunidade na turma que conduz, devendo por isso ter um elevado grau de inteligência interpessoal, responsável por sustentar o relacionamento entre os diversos atores na EaD (MAIA; MATTAR, 2007).

O tutor deve, ainda, auxiliar os alunos na interpretação do material visual e multimídia, já que muitas vezes os estudantes não possuem essa capacidade, o que pode prejudicar o andamento do curso. Aqui, ele desempenha um papel tecnológico.

A codificação para as funções dos tutores nesta pesquisa foi baseada em Amaro (2012), que, seguindo perspectiva próxima à de Bonk e Dennen (2003), identifica quatro categorias de funções/tarefas desempenhadas pelos tutores online, caracterizadas muitos anos antes por Berge (1995, 1996) como funções do professor a distância: gerencial (gerenciamento do curso), pedagógica (que inclui tudo que é feito para apoiar o processo de aprendizagem), social (em que estimula as relações humanas) e suporte técnico (domínio da tecnologia e acompanhamento do fluxo de aprendizagem).

Segundo Teles (2009), essas quatro áreas de conteúdo temático teriam sido também reconhecidas por outros autores. Blanchette (1999), por exemplo, ao analisar mensagens postadas em 
um curso online, teria identificado quatro temas principais, que capturariam a essência do trabalho do professor online: administrativo, conteúdo do curso, social e técnico. Blanchette teria, então, estabelecido uma conexão entre estas quatro áreas temáticas e as quatro funções do professor online desenvolvidas por Berge. Estas quatro funções foram ainda usadas como modelo para propor estratégias para a sala de aula virtual (PALLOFF; PRATT, 2002).

Nas primeiras leituras dos textos selecionados para a revisão de literatura, mostrou-se necessário distinguir quando as competências ou funções correspondentes a esses códigos eram, de um lado, utilizadas em revisões bibliográficas e reflexões teóricas, e quando, de outro lado, eram resultados de pesquisas empíricas conduzidas pelos autores dos textos, que é o interesse específico deste trabalho. Assim, os códigos classificados em Teoria (Quadro 2) são oriundos de reflexões teóricas e revisões bibliográficas nos textos selecionados para leitura (ou seja, não são resultado das pesquisas empíricas); já os mesmos códigos classificados em Pesquisa são o resultado de pesquisas empíricas realizadas nos estudos.

Dessa maneira, os códigos que guiaram inicialmente a análise dos textos selecionados para a revisão de literatura estão representados no Quadro 2, baseados, como indicado, em Tecchio et al (2010) e Amaro (2012).

Quadro 2 - Codificação inicial para leituras

1 Teoria

1.1 Competências

\subsubsection{Competências Técnicas}

1.1.1.1 Conhecimento das rotinas de trabalho

1.1.1.2 Conhecimento em informática básica/ambiente virtual de ensino-aprendizagem

1.1.1.3 Conhecimento pleno da disciplina ministrada

1.1.1.4 Conhecimento sobre educação a distância/sobre o curso

1.1.1.5 Relacionamentos interpessoais

1.1.1.6 Comunicação (oral/escrita)

1.1.1.7 Trabalho em equipe

1.1.2 Competências Comportamentais

1.1.2.1 Organização e Planejamento

1.1.2.2 Pró-atividade

1.1.2.3 Automotivação

1.1.2.4 Capacidade de síntese e análise

1.1.2.5 Empatia

1.1.2.6 Equilíbrio emocional

1.1.2.7 Flexibilidade

1.1.2.8 Comprometimento e Assiduidade

1.1.2.9 Liderança

1.1.2.10 Criatividade

1.2 Funções

1.2.1 Gerenciais

1.2.2 Pedagógicas

1.2.3 Sociais

1.2.4 Técnicas

2 Pesquisa

Educação em Revista|Belo Horizonte|v.36|e217439|2020 
2.1 Competências

2.1.1 Competências Técnicas

2.1.1.1 Conhecimento das rotinas de trabalho

2.1.1.2 Conhecimento em informática básica/ambiente virtual de ensino-aprendizagem

2.1.1.3 Conhecimento pleno da disciplina ministrada

2.1.1.4 Conhecimento sobre educação a distância/sobre o curso

2.1.1.5 Relacionamentos interpessoais

2.1.1.6 Comunicação

2.1.1.7 Trabalho em equipe

2.1.2 Competências Comportamentais

2.1.2.1 Organização e Planejamento

2.1.2.2 Pró-atividade

2.1.2.3 Automotivação

2.1.2.4 Capacidade de síntese e análise

2.1.2.5 Empatia

2.1.2.6 Equilíbrio emocional

2.1.2.7 Flexibilidade

2.1.2.8 Comprometimento e Assiduidade

2.1.2.9 Liderança

2.1.2.10 Criatividade

2.2 Funções

2.2.1 Gerenciais

2.2.2 Pedagógicas

2.2.3 Sociais

2.2.4 Técnicas

Fonte: elaborado pelos autores a partir de Tecchio et al (2010) e Amaro (2012).

Durante as leituras dos 34 textos selecionados para a revisão de literatura, os códigos foram arrastados, no software MAXQDA, para as palavras ou passagens dos textos em que podiam representar seus sentidos. Entretanto, rapidamente se mostrou necessário incluir novos códigos no quadro, já que algumas passagens dos textos não se enquadravam em nenhum dos códigos inicialmente propostos. Foi então utilizada a estratégia de codificação in vivo (SALDAÑA, 2016), um procedimento respaldado na grounded theory (ou teoria fundamentada), em que palavras ou expressões encontradas nos próprios textos são transformadas em códigos.

Após o longo trabalho de codificação e extração de dados dos 34 textos, a análise dos resultados levou em consideração a frequência das ocorrências dos códigos nos textos, além de reflexões e comparações diversas entre os códigos, suas respectivas passagens nos textos, as anotações feitas durante o processo de codificação no software MAXQDA e o referencial teórico utilizado, com retorno aos textos originais integrais em vários momentos.

\section{RESULTADOS E ANÁLISE}

É interessante analisar inicialmente a distribuição dos códigos em relação aos 34 documentos estudados, comparando sua ocorrência em reflexões teóricas e como resultado de pesquisas empíricas (tabelas 1 e 2). 
Tabela 1 - Distribuição dos códigos por documentos (teoria)

\begin{tabular}{lrrr} 
& Documentos & Porcentagem & Porcentagem (válida) \\
Competências (teoria) & 22 & 64,71 & 84,62 \\
\hline Funções (teoria) & 20 & 58,82 & 76,92 \\
\hline Documentos com código(s) & 26 & 76,47 & 100,00 \\
\hline Documentos sem código(s) & 8 & 23,53 & - \\
\hline Documentos analisados & 34 & 100,00 & - \\
\hline
\end{tabular}

Fonte: elaborada pelos autores por meio do software MAXQDA.

Tabela 2 - Distribuição dos códigos por documentos (pesquisa)

\begin{tabular}{lrrr} 
& Documentos & Porcentagem & Porcentagem (válida) \\
Competências (pesquisa) & 26 & 76,47 & 86,67 \\
\hline Funções (pesquisa) & 16 & 47,06 & 53,33 \\
\hline Documentos com código(s) & 30 & 88,24 & 100,00 \\
\hline Documentos sem código(s) & 4 & 11,76 & - \\
\hline Documentos analisados & 34 & 100,00 & -
\end{tabular}

Fonte: elaborada pelos autores por meio do software MAXQDA.

É possível notar que, apesar de a distribuição entre teoria e pesquisa ser proporcionalmente equilibrada no caso das competências $(84,62 \%$ e 86,67\%), os textos analisados exploram mais as funções do tutor na teoria do que na prática $(76,92 \%$ e 53,33\%). Ou seja, em relação às competências dos tutores online em educação a distância, há uma distribuição equitativa nos 34 textos analisados entre discussões teóricas e resultados de pesquisas empíricas, enquanto no caso das funções dos tutores, há significativamente mais discussões teóricas do que resultados de pesquisas empíricas.

A Tabela 3 mostra o resultado do processo de análise, incluindo agora novos códigos, criados durante a análise, e a frequência da ocorrência de todos os códigos nos textos. Percebe-se que um mesmo código poderia ser arrastado para mais de uma passagem do mesmo texto, ou seja, as contagens da Tabela 3 podem representar que um mesmo código se repetiu por duas ou mais vezes no mesmo texto.

Tabela 3 - Distribuição final da codificação

\begin{tabular}{lr}
\multicolumn{1}{l}{ 1 Teoria } & 0 \\
\hline 1.1 Competências & 19 \\
\hline 1.1.1 Competências Técnicas & 2 \\
\hline 1.1.1.1 Conhecimento das rotinas de trabalho & 2 \\
\hline 1.1.1.2 Conhecimento em informática básica/ambiente virtual de ensino- & 22 \\
\hline aprendizagem & 19 \\
\hline 1.1.1.3 Conhecimento pleno da disciplina ministrada & 11 \\
\hline 1.1.1.4 Conhecimento sobre educação a distância/sobre o curso & 8 \\
\hline 1.1.1.6 Comunicação (oral/escrita) & 9 \\
\hline 1.1.1.7 Trabalho em equipe & 7 \\
\hline 1.1.1.8 Gerenciais (nova) & 2 \\
\hline 1.1.1.9 Avaliação (nova) & 5 \\
\hline 1.1.1.10 Pedagógicas (nova) & 27 \\
\hline 1.1.1.11 Classificar & 4 \\
\hline 1.1.2 Competências Comportamentais & 1 \\
\hline 1.1.2.1 Organização e Planejamento & 6 \\
\hline
\end{tabular}


1.1.2.2 Pró-atividade

1.1.2.3 Automotivação

0

1.1.2.4 Capacidade de síntese e análise

1.1.2.5 Empatia

14

1.1.2.6 Equilíbrio emocional

6

1.1.2.7 Flexibilidade

2

1.1.2.8 Comprometimento e Assiduidade

0

1.1.2.9 Liderança

3

1.1.2.10 Criatividade

1.1.2.11 Motivar os Alunos (nova)

0

1.1.2.12 Socioafetivas (nova)

1.1.2.13 Respeito (nova) 17

1.1.2.14 Responsabilidade (nova)

1.1.2.15 Tomada de Decisão (nova)

1.1.2.16 Agilidade (nova)

1.1.21.7 Reflexão (nova)

1.1.2.18 Classificar

2 Funções

20

1.2.1 Gerenciais

1.2.2 Pedagógicas 76

1.2.3 Sociais 68

1.2.4 Técnicas 38

1.2.5 Polidocência (nova)

1.2.6 Classificar

2.1 Competências

2.1.1 Competências Técnicas

2.1.1.1 Conhecimento das rotinas de trabalho

2.1.1.2 Conhecimento em informática básica/ambiente virtual de ensinoaprendizagem

2.1.1.3 Conhecimento pleno da disciplina ministrada

2.1.1.4 Conhecimento sobre educação a distância/sobre o curso

2.1.1.5 Relacionamentos interpessoais

2.1.1.6 Comunicação (oral/escrita)

2.1.1.7 Trabalho em equipe

2.1.1.8 Gerenciais (nova)

2.1.1.9 Avaliação (nova)

2.1.1.10 Pedagógicas (nova)

2.2.2.11 Classificar 
2.1.2.1 Organização e Planejamento

2.1.2.2 Pró-atividade

2.1.2.3 Automotivação

2.1.2.4 Capacidade de síntese e análise

2.1.2.5 Empatia

2.1.2.6 Equilíbrio emocional

2.1.2.7 Flexibilidade

2.1.2.8 Comprometimento e Assiduidade

2.1.2.9 Liderança

7

2.1.2.10 Criatividade

2.1.2.11 Motivar os Alunos (nova)

2.1.2.12 Socioafetivas (nova)

2.1.2.13 Respeito (nova)

2.1.2.14 Responsabilidade (nova)

2.1.2.15 Tomada de Decisão (nova)

2.1.2.16 Agilidade (nova)

2.1.2.17 Reflexão (nova)

2.1.2.18 Classificar

7

\begin{tabular}{lr}
2.2 Funções & 1 \\
2.2 .1 Funções Gerenciais & 25 \\
\hline 2.2 Funções Pedagógicas & 56 \\
\hline 2.2 .3 Funções Sociais & 37 \\
2.2 .4 Funções Técnicas & 4 \\
2.2 .5 Polidocência (nova) & 0 \\
\hline 2.2 .6 Classificar & 1 \\
\hline
\end{tabular}

Fonte: elaborada pelos autores a partir de Tecchio et al (2010) e Amaro (2012) e da codificação in vivo (SALDAÑA, 2016) a partir da análise dos 34 textos selecionados para a revisão de literatura, produzida no software MAXQDA.

Algumas análises iniciais podem ser feitas em relação aos resultados da codificação dos textos, ainda antes da discussão.

Como já mencionado, tanto nas competências quanto nas funções dos tutores, na teoria e na pesquisa, foi necessário criar novos códigos, identificados na Tabela 3 entre parênteses: (nova). Além disso, em todos os níveis foi criada uma categoria denominada Classificar, quando não foi possível vincular algumas passagens aos códigos existentes, e nem se justificava criar um novo código. Uma leitura posterior das palavras ou passagens associadas a essa categoria Classificar gerou algumas reclassificações em outros códigos, quando isso se demonstrou significativo para a análise, que já contabilizadas no resultado apresentado.

De um total de 795 códigos aplicados a passagens dos 34 textos, 57\% (455) estão classificados em competências e 43\% (340) em funções. Se considerarmos apenas os resultados das pesquisas empíricas, a diferença é ainda maior (68\% para competências e $32 \%$ para funções). Nesse sentido, pode-se afirmar que, na literatura em língua portuguesa, há uma preferência por pesquisas sobre as competências dos tutores, em comparação com pesquisas sobre suas funções.

De um total de 455 códigos classificados em competências, 57\% (260) o foram em competências técnicas e 43\% (195) em competências comportamentais. A proporção é mais ou menos a mesma quando consideramos apenas os resultados de pesquisas empíricas ( $55 \%$ a $45 \%$ ). Levando-se 
em consideração que o número de códigos para as competências técnicas (11) é sensivelmente menor do que o número de códigos para as competências comportamentais (18), é possível perceber uma preferência da literatura em língua portuguesa por pesquisas sobre competências técnicas (conhecimentos e habilidades) em relação às competências comportamentais (atitudes).

A quantidade de codificações com os novos códigos (24\%) foi sensivelmente menor do que com os códigos propostos antes do início da leitura dos textos $(76 \%)$, o que em princípio demonstra a solidez das pesquisas de Tecchio et al (2010) e Amaro (2012), utilizadas como base para o esquema inicial de codificação. Entretanto, uma análise mais cuidadosa desvela resultados distintos. Quando consideramos apenas as competências, a relação entre códigos novos e originais é de $36 \%$ e $64 \%$, enquanto se consideramos as funções, a relação é de $8 \%$ (códigos novos) e $92 \%$ (códigos originais). Isso parece demonstrar que o modelo de Amaro (2012) para a análise das funções dos tutores é mais sólido do que o proposto por Tecchio et al (2010) para a análise das competências dos tutores, cabendo ainda lembrar que há um número muito maior de códigos originais para competências (17) do que para funções (apenas 4). No mesmo sentido, há um desequilíbrio muito grande entre o total de codificações novas em competências $(86 \%)$ em relação a funções (14\%), reforçando a ideia de que o modelo de Amaro é mais adequado para seus propósitos.

Em relação aos códigos individuais, é importante notar que poucos se destacaram em função de sua recorrência, tanto em discussões teóricas quanto em pesquisas empíricas, conforme a Tabela 4.

Tabela 4 - Códigos com recorrência significativa

\begin{tabular}{|l|r|r|}
\hline & \multicolumn{1}{|c|}{ Teoria } & \multicolumn{1}{c|}{ Pesquisa } \\
\hline Competências & & \\
\hline Técnicas & & \\
\hline conhecimento em informática básica/ambiente virtual de ensino-aprendizagem & 22 & 23 \\
\hline conhecimento pleno da disciplina ministrada & 19 & 9 \\
\hline comunicação & 27 & 31 \\
\hline pedagógicas (nova) & & \\
\hline Comportamentais & 14 & 15 \\
\hline empatia & 17 & 14 \\
\hline socioafetivas (nova) & & \\
\hline Funções & 76 & 25 \\
\hline gerenciais & 68 & \\
\hline pedagógicas & 38 & 56 \\
\hline sociais & & 37 \\
\hline
\end{tabular}

Fonte: os autores, resultados da codificação dos textos utilizando o software MAXQDA.

Além disso, cabe mencionar, especificamente como resultado de pesquisas empíricas, a competência comportamental de organização e planejamento (com 16 recorrências). Dentre as competências, deve-se ressaltar que as pedagógicas e socioafetivas não constavam dos códigos originais, o que merecerá uma discussão específica na próxima seção.

Interessante também notar que alguns códigos originais apresentaram recorrência pífia nas pesquisas, como as competências de automotivação, capacidade de síntese e análise e equilíbrio emocional, além da função técnica, que apareceu apenas 7 vezes nas discussões teóricas e 4 vezes como resultado de pesquisas empíricas.

\section{DISCUSSÃO}

Tecchio et al (2010) não elaboram uma diferenciação significativa entre as competências técnicas e comportamentais dos tutores, o que, entretanto, é realizado por Coelho Junior et al (2013). As competências técnicas compreenderiam os conhecimentos e as habilidades "diretamente relacionadas ou proximais ao conjunto de atribuições e responsabilidades de um cargo ou função", enquanto as competências comportamentais se refeririam "a atitudes e habilidades mais distais ao cargo, mas compatíveis com as atribuições que devem ser desempenhadas" (COELHO JUNIOR et al, 2013, p. 882). As competências técnicas seriam, portanto, "diretamente relacionadas ao exercício profissional das tarefas e atribuições", enquanto as competências comportamentais estariam "relacionadas às formas pelas quais os indivíduos agem, se relacionam socialmente e interagem entre si" (COELHO JUNIOR et 
al, 2013, p. 885). Habilidades mais proximais à atuação do tutor foram, nesse sentido, consideradas competências técnicas. Os autores segmentam ainda as competências técnicas em cognitivas, que envolveriam "tipos de conhecimentos e habilidades essenciais à organização e planejamento do trabalho do tutor, além de requisitos pessoais básicos esperados em sua atuação", e funcionais, "relativas à construção da prática pedagógica do tutor para com seus alunos, numa visão interacional” (COELHO JUNIOR et al, 2013, p. 887).

Entretanto, a análise dos textos selecionados para a revisão de literatura mostrou que a separação entre competências comportamentais e técnicas nem sempre se sustenta. Pareceu fazer mais sentido segmentar as competências no tradicional CHA (conhecimentos, habilidades e atitudes). Para Schneider (2014, p. 80), por exemplo:

[...] os conhecimentos oferecem a base de conceitos e significações para lidar com o problema, as habilidades integram as técnicas e procedimentos para aplicar os conhecimentos e as atitudes fornecem meios através da afetividade e da escala de valores para que, finalmente, apliquem-se as competências.

Em lugar de atitudes, Carvalho (2009, p. 64) refere-se a recursos pessoais, "traços, características da personalidade do tutor, desejáveis para que ele possa mobilizar frente a situações complexas de sua atividade profissional". A combinação e a mobilização de conhecimentos, habilidades e recursos pessoais gerariam ações competentes.

Perrenoud (2000) explora as competências pedagógicas, um dos códigos novos que teve recorrência significativa nos textos analisados, o que justifica sua inclusão como categoria no modelo que será proposto. Apesar de suas obras estarem voltadas para a educação presencial, vários autores, como, por exemplo, Nobre e Melo (2011), propõem a adaptação de suas ideias para o tutor na educação a distância.

Tardif (2010), entretanto, utilizado como referencial teórico por vários dos textos analisados na revisão de literatura, prefere o termo "saberes" a "competências". Os saberes englobariam tanto as competências, quanto os conhecimentos, as habilidades e as atitudes docentes, ou seja, tanto "saber", quanto "saber fazer" e "saber ser". As ideias do pesquisador canadense são utilizadas para fundamentar a concepção do tutor a distância cuja formação se desenvolve em sua própria experiência profissional de mediação docente. Chaquime (2014), por exemplo, reflete sobre conhecimentos e saberes que se desenvolveriam a partir das experiências que o tutor vivencia em seu cotidiano, em um processo de formação continuada e de aprender fazendo, na prática. Para a autora, inclusive, saberes não deveriam ser entendidos simplesmente como um componente das competências, mas poderiam ser utilizados em seu lugar, pois teriam uma conotação mais pessoal do que a impessoalidade do termo competências, valorizando-se assim o professor como um sujeito ativo no processo de ensino e aprendizagem.

Costa, Siewerdt e Rausch (2011, p. 7937) também ressaltam a diferença de sentido entre saberes e competências:

Os saberes docentes surgem como marca da produção intelectual, com o desenvolvimento de
estudos que utilizam uma abordagem téorico-metodológica que dá voz ao professor, a partir da
análise de trajetórias, histórias de vida. Segundo Nóvoa (1995), esta nova abordagem veio em
oposição aos estudos anteriores que acabavam por reduzir a profissão docente a um conjunto
de competências e técnicas, gerando uma crise de identidade dos professores em decorrência de
uma separação entre o eu profissional e o eu pessoal. Essa vertente nas investigações passou a
ter o professor como foco central em estudos e debates, considerando o quanto o "modo de
vida" pessoal acaba por interferir no profissional. Esse autor acrescenta ainda que esse
movimento surgiu "num universo pedagógico, num amálgama de vontades de produzir outro
tipo de conhecimento, mais próximo das realidades educativas e do quotidiano dos professores"
(NÓVOA, 1995, p. 19).

Essa discussão teórica leva a observar que o conceito de saberes é, de um lado, classificado por alguns autores no interior do campo semântico coberto pelas competências, mais ou menos identificado com o significado de conhecimentos. Outros autores, entretanto, posicionam os saberes no nível do conceito de competências, ou até mesmo o envolvem, posicionando-os do lado de fora desse campo semântico, de forma a englobar não apenas as competências, mas também as habilidades, os conhecimentos e as atitudes. Considerando essas variações semânticas, o modelo proposto neste artigo 
posiciona Saberes (com S maiúsculo) como variação de Competências, e saberes (com s minúsculo) como variação de conhecimentos, um dos componentes das Competências (ou dos Saberes).

A formação oferecida aos professores pelas instituições não esgotaria os saberes dos tutores, que seriam também constituídos pelos saberes pedagógicos resultantes da reflexão sobre sua prática no contexto do trabalho, caracterizando, assim, uma formação continuada. Novamente, encontra-se aqui um reforço para a inclusão do saber (ou competência) pedagógico em um modelo que procure fundamentar o exercício da tutoria online e programas de formação de tutores.

Englobadas pelos saberes docentes, destacam-se também as relações afetivas com os alunos nos ambientes virtuais. Cabe, nesse sentido, lembrar de outro código novo que apresentou recorrência significativa nos textos analisados, a competência socioafetiva, que, para Aretio (2002), por exemplo, conforme já mencionado, envolveria cordialidade, capacidade de aceitação, honradez e empatia.

Os saberes necessários ao exercício da docência, segundo Tardif (2010), poderiam ser classificados em: disciplinares (em relação aos campos de conhecimento), profissionais (ou pedagógicos, oriundos da formação profissional), curriculares (englobando programas, objetivos, conteúdos e métodos organizados e apresentados pela instituição escolar) e experienciais (adquiridos na prática docente). A partir da combinação desses saberes, os professores constituiriam a base necessária para saber ensinar.

O conhecimento do conteúdo da disciplina corresponderia ao que Tardif denomina saberes disciplinares. Cabe lembrar que o código "conhecimento pleno da disciplina ministrada" apresentou recorrência significativa nos textos analisados na revisão de literatura, justificando assim sua inclusão no modelo proposto.

Já justificamos mais de uma vez a inclusão das competências pedagógicas no modelo proposto, que não faziam parte da categorização inicial. Os saberes profissionais ou pedagógicos, para Tardif, incluiriam a formação profissional docente transmitida por instituições de formação de professores. Em um sentido mais amplo, o conceito de saberes pedagógicos poderia incluir não apenas os saberes profissionais, como também os curriculares, ou seja, os discursos, os objetivos, os conteúdos e as metodologias "selecionados pelas instituições educacionais como modelos para formar e transmitir a cultura erudita" (CHAQUIME, 2014, p. 111-112). É importante notar que esses saberes curriculares não se mostraram recorrentes nos textos analisados na revisão de literatura, justificando, assim, sua inclusão como subcategoria da categoria mais ampla dos saberes pedagógicos, além de poderem ser considerados saberes experienciais, específicos, que o docente adquiriria naturalmente em sua prática ou seja, não necessariamente uma competência prévia que ele deveria possuir.

Cabe, ainda, abordar justamente o que Tardif chama de saberes experienciais, que representariam a sabedoria da prática profissional da docência. Nesse sentido, é natural conceber que cursos de formação de professores deveriam ser desenvolvidos, em grande parte, como experiências de práticas. Ou seja, os saberes experienciais, apesar de não fazerem parte do quadro teórico das competências e funções dos tutores, devem ser fundamento metodológico de cursos de formação de tutores.

Já os códigos que fundamentaram as funções dos tutores (gerenciais, pedagógicas, sociais e técnicas) estavam baseados em Amaro (2012), que por sua vez se baseou em Teles (2009), que por sua vez se baseou nas categorias que Berge $(1995,1996)$ identificou nos professores online.

Em primeiro lugar, caberia perguntar: deveríamos distinguir funções de atividades? Maia (2014, p. 233-234), por exemplo, faz um mapeamento de dez atividades (ou ações) do tutor e diversas subatividades. Alguns autores falam também de papéis e tarefas dos tutores.

Todavia, independente da denominação, não se encontra na literatura grande variação em relação às categorias propostas para as funções dos tutores. Aretio (2002), por exemplo, fala de tarefas de orientação, acadêmica, conexão e institucional. Moore e Kearsley (2007), por sua vez, exploram os saberes, as capacidades, as atividades e as funções dos tutores, que dividem em quatro: ensino, acompanhamento do progresso do aluno (com destaque para o feedback), apoio ao aluno e contribuições para o aperfeiçoamento geral do sistema.

Dos quatro códigos utilizados inicialmente em relação às funções docentes, apenas as funções técnicas não apresentaram recorrência significativa nos textos analisados, não tendo sido, por isso, incluídas no modelo proposto. Cabe notar que Duarte (2008), utilizando as mesmas funções, 
encontrou apenas $0,49 \%$ de mensagens relacionadas à função de suporte técnico. A explicação para esse fato talvez esteja na origem dessas categorias estar vinculada a pesquisas publicadas em 1995 e 1996 (primórdios da internet e, portanto, da educação a distância online), quando as equipes de $\mathrm{EaD}$ ainda não eram suficientemente desenvolvidas e multifacetadas, tendo o professor online que exercer, na época, funções técnicas que, naturalmente, passaram a ser desempenhadas por outros profissionais, como suporte técnico e monitores. Além disso, cabe lembrar que Prensky (2001), alguns anos depois das pesquisas iniciais de Berge $(1995,1996)$, cunhou as expressões nativos digitais e imigrantes digitais, tendo posteriormente revisado esses conceitos e passado a trabalhar com a expressão sabedoria digital (PRENSKY, 2012), pois não haveria mais sentido em enxergar na idade uma diferenciação tão marcante de gerações em relação ao uso de tecnologias. Os alunos passaram naturalmente a participar da educação a distância online com cada vez mais conhecimentos de tecnologias, o que acabou também retirando do docente a responsabilidade por desempenhar várias tarefas técnicas.

O modelo proposto neste artigo (Quadro 3) procura traçar correspondências entre algumas competências e funções dos tutores online. Importante registrar que esse exercício explícito de relação entre competências e funções não foi identificado nos textos analisados na revisão de literatura.

Em função do que já foi discutido nesta seção, foram alteradas, em relação à codificação original, palavras ou expressões para definir algumas competências (em alguns casos, agora saberes). Algumas competências poderiam ter sido distribuídas por mais de uma coluna, mas preferimos tentar manter a identificação mais próxima com um dos elementos do CHA (conhecimentos, habilidades e atitudes), com exceção das competências gerenciais. Algumas funções foram distribuídas por mais de uma linha, para deixar claro que podem corresponder a mais de um tipo de competência.

Maiúsculas em Saberes e minúsculas em saberes são utilizadas para diferenciar os sentidos da palavra, como já discutido. Atividades, tarefas e papéis podem ser usadas como variações para Funções.

Quadro 3 - Modelo de competências e funções do tutor online

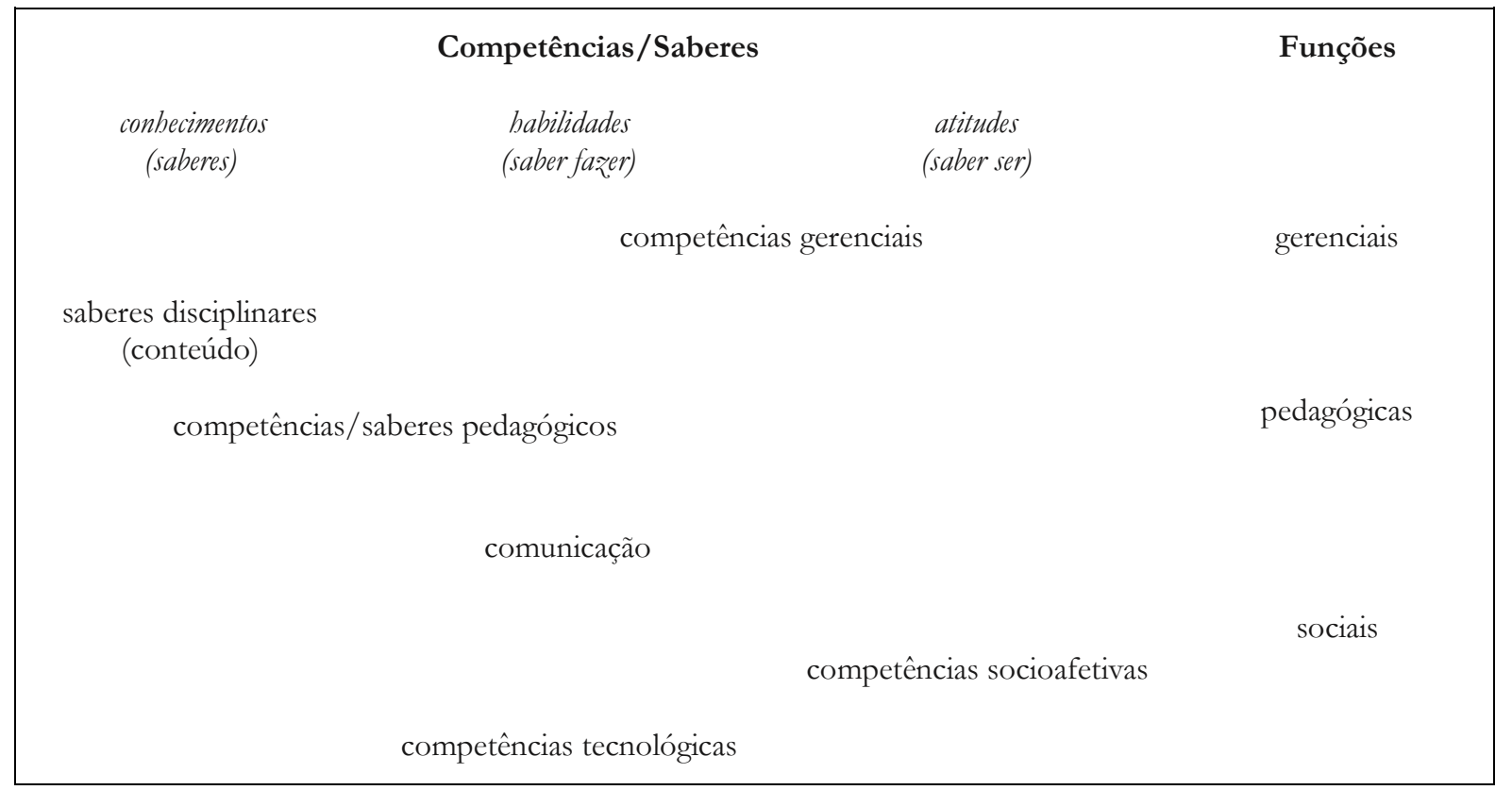

Fonte: Elaborado pelos autores, a partir da codificação e categorização dos textos selecionados para a revisão de literatura

Alguns dos códigos propostos para a análise de dados não foram cobertos pelo modelo. Entretanto, não nos pareceu necessário incorporar todos eles. Alguns tiveram recorrência insignificante na revisão de literatura, e outros provavelmente são muito gerais, ou seja, não específicos à atuação de um tutor online.

\section{Competências e funções gerenciais}

Tecchio et al (2010) definem a competência comportamental de organização e planejamento, de uma maneira geral, como a "capacidade para determinar o conjunto de procedimentos, ações 
necessárias para a consecução das atividades de forma organizada, com o intuito de aperfeiçoar os procedimentos e conseguir melhores resultados". Na pesquisa de Tenório, Gama e Tenório (2015), ser organizado foi considerado o atributo mais importante para um tutor em sua prática. Interessante notar que a pesquisa de Maia (2014) demonstrou que, em relação a organização e planejamento, a maioria dos tutores encontrava-se acima da nota 9 (de 0 a 10), demonstrando um nível avançado de domínio da competência.

Schneider (2014, p. 63-64) distingue organização, planejamento e administração do tempo.

Organização: competência focada na capacidade de estabelecer contato permanente com os alunos e mediar as atividades discentes. A organização também será essencial à elaboração de relatórios mensais de acompanhamento dos alunos e ao encaminhamento desse material periodicamente à Coordenação de Tutoria.

$[\ldots]$

Planejamento: competência fundamentada no planejamento das atividades de tutoria e na seleção de estratégias adequadas ao grupo.

$[\ldots]$

Administração do tempo: capacidade de organizar sua agenda de compromissos, a fim de manter regularidade de acesso ao AVA e de dar retorno às solicitações do cursista dentro do prazo estabelecido (24 horas).

De acordo com Borges Júnior et al (2014), o tutor de EaD seria um administrador e um gestor, para dar conta de exigências da instituição, e, por isso, além de organização e planejamento, seu trabalho envolveria também competências de coordenação e controle. Nesse sentido, apesar de Tecchio et al (2010) denominarem essa competência "organização e planejamento", outros autores, citando diversos trabalhos, utilizam a denominação competências "gerenciais" (ALMEIDA; MARROIG; PINTO, 2014; TENÓRIO; ALMEIDA; TENÓRIO, 2015; TENÓRIO; BEZERRA; TENÓRIO, 2015). Considerando que as funções gerenciais são consagradas na literatura e correspondem diretamente a essas competências, essa denominação foi utilizada no modelo proposto neste artigo. Sob as competências gerenciais, estaria incluída também a competência de tomada de decisões, que arriscamos durante a análise como um código novo, mas que praticamente não teve ressonância nos textos analisados na revisão de literatura.

O tutor exerce uma função de intermediário entre os alunos, os professores, a equipe de EaD e a instituição. Nesse sentido, Maia (2014), por exemplo, faz menção de uma função institucional. Para Amaro (2012), as funções gerenciais dos tutores envolveriam atividades administrativas em relação ao curso. Para Teles (2009, p. 8-9), incluiriam todas atividades realizadas para que o curso se desenvolvesse de maneira eficiente no nível administrativo, podendo ser subdividas em três categorias: gerenciar a parte administrativa do curso (por exemplo: esclarecer regras e expectativas), gerenciar as ações dos alunos (por exemplo, encorajá-los a postar mensagens e entregar trabalhos dentro dos prazos) e administrar discussões e trabalhos em grupo (por exemplo: criar grupos, decidir sua composição, definir papéis e monitorar a interação). Duarte (2008), de maneira similar, divide as funções gerenciais em: coordenação da disciplina como um todo, coordenação das tarefas da disciplina e coordenação das discussões.

O feedback e a avaliação, nesse sentido, são classificados por alguns autores também como funções gerenciais, mas como são componentes essenciais do processo de ensino e aprendizagem, são considerados no modelo proposto neste artigo como funções pedagógicas.

\section{Saberes disciplinares}

Os saberes disciplinares equivalem ao conhecimento do conteúdo. Para Tecchio et al (2010), a competência técnica "conhecimento pleno da disciplina ministrada" corresponderia ao conhecimento e à capacidade de entendimento do conteúdo da disciplina a ser ministrada. Nesse sentido, pode-se falar em conteúdos técnico-científicos e em saberes científicos: o tutor deve ser um especialista no conteúdo 
da disciplina. Seria natural, portanto, que se exigisse de um tutor um nível acadêmico superior em relação ao curso no qual fosse exercer suas funções.

Dentre os tutores entrevistados por Borges, Coelho Junior, Faiad e Rocha (2014), por exemplo, um dos temas preponderantes foi o domínio de conteúdo, enquanto que os que foram entrevistados por Oliveira e Lima $(2014$, p. 215) “consideraram que ter o domínio dos conteúdos é uma competência fundamental para o exercício da tutoria e, consequentemente, elemento para que o curso tenha maior qualidade". Os saberes disciplinares, especialmente aqueles referentes ao domínio dos conteúdos trabalhados nas disciplinas e à competência para responder as dúvidas dos alunos referentes aos conteúdos, destacaram-se também na análise documental de editais de seleção de tutores e de projetos pedagógicos de cursos de Pedagogia, assim como em questionários aplicados a coordenadores de curso e de tutoria, professores e tutores, na pesquisa de Oliveira e Lima (2014).

Mas não se espera que o tutor tenha apenas conhecimento do conteúdo: deve também manifestar "a competência de buscar, continuamente, conhecimento sobre a literatura relacionada à Disciplina, indicando, aos alunos, leituras complementares" (COELHO JUNIOR et al, 2013, p. 890). Além disso, os saberes disciplinares não se resumem ao conteúdo: devem também se estender aos materiais didáticos que serão utilizados no curso.

\section{Saberes pedagógicos e funções pedagógicas}

Para Almeida, Marroig e Pinto (2014), a dimensão pedagógica das competências do tutor envolveria a formação e a avaliação. Para Tenório, Almeida e Tenório (2015), de maneira similar, as competências pedagógicas englobam a capacidade de orientação, acompanhamento e avaliação do processo de ensino e aprendizagem.

Os saberes pedagógicos equivalem, no modelo proposto neste artigo, às competências pedagógicas, que possibilitam que os tutores realizem o trabalho de mediação pedagógica nos ambientes virtuais de aprendizagem.

Entre os saberes pedagógicos necessários ao tutor para desempenhar seu trabalho constam aqueles relacionados à competência para criar e trabalhar com grupos de estudos, orientar e estimular os estudos, propiciar a compreensão dos conteúdos, analisar o desempenho dos alunos e propor procedimentos para sua melhoria, avaliar a aprendizagem/o curso/a disciplina, orientar monografias e trabalhos de conclusão de curso, sugerir melhorias do material didático etc. (OLIVEIRA; LIMA, 2014, p. 5).

Concebemos no texto os saberes pedagógicos em um sentido amplo, incluindo tanto os saberes profissionais quanto os curriculares propostos por Tardif (2010). Mas Shulman (1987, p. 8, trad. dos autores) amplia ainda mais as possibilidades de definição desse campo:

Se o conhecimento docente fosse organizado em um manual, uma enciclopédia ou algum outro formato de sistematização do conhecimento, como seriam os títulos das categorias? No mínimo, incluiriam:

— conhecimento do conteúdo;

- conhecimento pedagógico geral, com referência especial àqueles princípios e estratégias amplos de gestão e organização da sala de aula que parecem transcender o conteúdo;

- conhecimento curricular, com compreensão específica dos materiais e programas que servem como "ferramentas de ofício" para os professores;

- conhecimento pedagógico do conteúdo, esse amálgama especial de conteúdo e pedagogia, que o domínio exclusivo dos professores, sua própria forma especial de compreensão profissional;

— conhecimento dos alunos e de suas características;

- conhecimento dos contextos educacionais, desde o funcionamento do grupos ou das salas de aula, a governança e o financiamento dos distritos escolares, até as características das comunidades e das culturas; e 
- conhecimento dos objetivos, propósitos e valores educacionais e seus fundamentos filosóficos e históricos.

Entre essas categorias, o conhecimento pedagógico do conteúdo reveste-se de interesse especial, pois identifica os campos de conhecimento específicos do ensino. Representa a mistura de conteúdo e pedagogia em uma compreensão de como determinados tópicos, problemas ou questões são organizados, representados e adaptados aos interesses e habilidades diversificados dos alunos, e apresentados para o ensino. O conhecimento pedagógico do conteúdo é a categoria mais apropriada para distinguir a compreensão do especialista em conteúdo da compreensão do pedagogo.

Nota-se que o conhecimento do conteúdo equivale ao que se denomina saberes disciplinares, além de que os conhecimentos curriculares estão incluídos no que chamamos de saberes pedagógicos, assim como o que Shulman denomina "conhecimento pedagógico geral". Mas Shulman chama ainda a atenção para o que denomina "conhecimento pedagógico do conteúdo", o "jeito" de ensinar, construído continuamente pelo tutor na prática da docência online, que se localizaria de alguma maneira na intersecção entre os saberes disciplinares e os saberes pedagógicos. Além disso, o tutor precisaria de habilidades para conhecer o perfil dos alunos, e poderiam estar aqui ainda incluídos alguns outros códigos originais que não encontraram recorrência nos textos analisados na revisão de literatura, como "conhecimento das rotinas de trabalho" e "conhecimentos sobre educação a distância/sobre o curso".

Os tutores pesquisados por Tenório, Teles e Tenório (2016) consideraram as competências pedagógicas vitais para o exercício da tutoria, e como competência pedagógica mais importante, a habilidade de desenvolver a capacidade crítica dos alunos.

O tutor não ensina propriamente dito: é um incentivador, facilitador, mediador e orientador da aprendizagem. Assim, para Teles (2009), as funções pedagógicas incluiriam todas as atividades realizadas para apoiar o processo de aprendizagem do indivíduo ou do grupo, podendo ser divididas em técnicas centradas na instrução direta e técnicas para facilitar a aprendizagem. Nesse sentido, exemplos de atos pedagógicos seriam:

1) instrução direta;

2) perguntas diretas;

3) referências a modelos ou exemplos;

4) dar conselhos ou oferecer sugestões;

5) promover autorreflexão no estudante;

6) guiar os estudantes no processo de encontrar outras fontes de informações;

7) sugerir que os estudantes expliquem ou elaborem melhor suas ideias;

8) oferecer feedback e congratulações pelas contribuições na discussão online;

9) atuar como suporte na estruturação das tarefas cognitivas;

10) “costurar" comentários com o objetivo de criar um único sumário e redirecionar a discussão com os estudantes para os eixos centrais mais importantes do tema (Teles, 2009, p. $7-8)$

Melani (2013) observa que em chats, fóruns e tarefas analisadas, oferecer "instrução direta" (1) foi o ato pedagógico que apresentou maior presença de registros de mensagens dos tutores, com destaque ainda para fazer "perguntas diretas" (2) e "oferecer feedback e congratulações pelas contribuições na discussão online" (8). Alguns desses atos, como o feedback e a mediação das discussões, podem se confundir com funções gerenciais e sociais; isso mereceria um trabalho de comparação e diferenciação que não será realizado neste artigo. A promoção da autonomia, o incentivo à pesquisa, a resposta a perguntas e dúvidas e a avaliação incluem-se dentre as funções pedagógicas.

Assim como em outras pesquisas (por exemplo, DUARTE, 2008; MELANI, 2013), dentre as funções do tutor online, a pedagógica foi a que apareceu com o maior número de códigos, 
configurando-se como a mais importante para o processo de aprendizagem. Mas é importante notar que a função pedagógica desempenhada pelo tutor tende a variar em função do modelo de educação a distância adotado pela instituição de ensino, envolvendo menor ou maior participação do professor, menor ou maior liberdade e flexibilidade para o trabalho do tutor, e assim por diante.

\section{Comunicação}

Deve-se ressaltar que as funções pedagógicas correspondem em nosso modelo não apenas às competências e aos saberes pedagógicos, mas também aos saberes disciplinares e a parte de outra competência que se destacou em nossa pesquisa, a comunicação, que corresponde também parcialmente às funções sociais.

De uma maneira geral, a competência da comunicação envolve a capacidade de receber e transmitir informações de forma clara, concisa, objetiva e pertinente no ambiente de trabalho. Nesse sentido, a "capacidade de síntese e análise" e o "trabalho em equipe", códigos propostos no início da análise, mas que não encontraram ressonância nos textos analisados, poderiam ser classificados nesta categoria, apesar de o último também poder ser parcialmente classificado como competência socioafetiva.

No caso do tutor online, a fluência na comunicação escrita em língua portuguesa mostra-se essencial.

A comunicação é a principal via de interação entre tutor e demais atores sociais envolvidos na modalidade de ensino a distância. Assim, é importante que o mesmo se comunique, por escrito e verbalmente, de maneira clara, educada e objetiva, evitando maus entendimentos, erros de interpretação e de compreensão. É imprescindível, também, expressar-se por escrito atendendo à norma culta da Língua Portuguesa, de modo que o aluno não perceba erros em suas ponderações. (COELHO JUNIOR et al, 2013, p. 890).

É importante notar que se espera que o tutor online saiba se comunicar com clareza e precisão, mas, mais especificamente, interagir com os alunos por escrito no ambiente virtual de aprendizagem, ou seja, de forma não presencial.

Maia (2014) sugere indicativos para mensurar a competência da comunicação oral e escrita do tutor online: é comunicativo e identificado com o grupo de alunos; envia respostas sucintas, porém sem alterar o significado; é objetivo ao passar informações; prende a atenção das pessoas com facilidade; sabe ouvir; sabe escrever corretamente em português; e possui linguagem escrita correta, sem usar gírias.

Diversas pesquisas realizadas com tutores destacaram a comunicação como uma competência essencial. Para os tutores pesquisados por Tenório, Pires e Tenório (2017), por exemplo, a comunicabilidade foi apontada como fundamental para sua atuação adequada, por incentivar a participação dos alunos. Para os pesquisados por Tenório, Gama e Tenório (2015), ser comunicativo foi considerado o principal atributo de personalidade requerido de um tutor. Nas falas dos tutores pesquisados por Grützmann e Pino (2013), a comunicação foi caracterizada como um saber imprescindível para a relação a ser estabelecida com os alunos, e estratégico para o sucesso do processo de aprendizagem, constituindo, assim, a identidade profissional dos tutores.

\section{Competências socioafetivas e funções sociais}

Um dos códigos criados durante o processo de análise, e que se mostrou recorrente nos textos, foi o de competências socioafetivas. Esta categoria acabou assumindo no modelo um espectro bem amplo, abarcando vários códigos que não tiveram recorrência significativa nos textos analisados, como empatia, flexibilidade, respeito, relacionamentos interpessoais, estimular e motivar os alunos.

Oliveira e Lima (2014, p. 6) falam de saberes "relacionados à capacidade do tutor para promover a afetividade e a criação de vínculos com alunos". As competências socioafetivas envolveriam, portanto, a capacidade de o tutor se relacionar e construir vínculos afetivos e sociais com os alunos e administrar conflitos, estimulando, assim, a interação e promovendo a aprendizagem coletiva. Essa habilidade propiciaria uma atmosfera favorável à aprendizagem, ao tornar o ambiente virtual, no qual faltam indícios e sinais não verbais, mais acolhedor, seguro e humanizado. Para isso, o tutor precisa se fazer sentir presente no ambiente.

Educação em Revista|Belo Horizonte|v.36|e217439|2020 
A tutoria exerce suas funções também no âmbito do afetivo, das atitudes e emoções. Sua ação deve se dar no sentido de observar as diferenças individuais, conhecer e estimular o aluno para que se identifique e se integre ao curso, evitando a ansiedade e a solidão. São essenciais também a comunicação individual, as demonstrações de aceitação e compreensão, o trabalho com as dificuldades, a consciência de que ambos são aprendentes e ensinantes nesse processo interativo. (OLIVEIRA, 2009, p. 13).

Em síntese, a afetividade é um recurso de mobilização que permite ao indivíduo experimentar sentimentos positivos ou negativos associados aos objetos de conhecimentos (materiais, situações, animais e pessoas, incluindo a si mesmo) e a eles reagir. Cada fenômeno que influencia e/ou compõe a afetividade (emoções, estados de ânimo, preferências, disposições afetivas, posturas) difere em termos da origem, da função, da intensidade, da duração, das reações corporais e das ações comportamentais (BEHAR, 2013, p. 36-37).

$\mathrm{Na} \mathrm{EAD}$, a distância física provoca uma "dependência" afetiva como tutor mais forte que na modalidade presencial, porque o aluno não está em contato físico com seus colegas de turma. Por conta disso, ele recorre ao tutor em velocidade e intensidade maiores para pedir auxílio quando sente dificuldades de aprendizagem. O tutor deve, então, demonstrar segurança e compreensão para saber lidar com alunos que apresentarão, como qualquer ser humano, problemas de ordem pessoal, familiares, econômicos etc. (CARVALHO, 2009, p. 65).

e empatia.

Aretio (2002) destaca quatro competências socioafetivas: cordialidade, aceitação, honradez

A cordialidade implica fazer com que os alunos se sintam "bem-vindos" ao curso, respeitados e confortáveis. As pesquisas de Mendes et al (2015) e Tenório, Loos e Tenório (2017) detectaram sua importância como competência socioafetiva, assim como aceitação.

A aceitação implica compreender a realidade do aluno para que se sinta participante ativo do processo de ensino e aprendizagem. O diálogo e o respeito são, portanto, essenciais, especialmente levando-se em consideração a possível diversidade cultural entre os alunos. Nesse sentido, os tutores pesquisados por Mendes et al (2015, p. 140) "concordaram ser de suma importância estimular a aceitação e o respeito mútuo entre os cursistas para favorecer o companheirismo em um grupo diverso." Essas competências colaborariam com a humanização da educação a distância. Para mais de $50 \%$ dos tutores pesquisados por Tenório, Souto e Tenório (2014), por exemplo, a cordialidade foi considerada a principal competência socioafetiva a se exigir de um tutor a distância.

A honradez implica ser verdadeiro e autêntico. Está vinculada à honestidade e à ética, gerando confiança.

Por fim, a empatia, considerada no início da análise um código distinto, implica que o tutor se coloque no lugar dos alunos, envolvendo-se com seus sentimentos.

Os tutores pesquisados por Tenório, Pires e Tenório (2017) consideraram a socioafetividade essencial ao processo de ensino e aprendizagem, por criar vínculos entre tutor e alunos. Santos (2016) também considera imprescindível o desenvolvimento dessa competência.

Pode-se considerar que as competências socioafetivas apoiam de alguma maneira todas as demais competências e funções desempenhadas pelos tutores online.

\section{Competências tecnológicas}

As competências tecnológicas incluem habilidades com informática, softwares, ferramentas, mídias, tecnologias em geral, e os ambientes virtuais de aprendizagem em particular — poder-se-ia, nesse sentido, falar de letramento e fluência digital do tutor online. Da mesma forma que se pode falar de saberes pedagógicos do conteúdo, seria possível falar de saberes pedagógicos da tecnologia, ou seja, as habilidades para se ensinar no ambiente virtual.

As competências tecnológicas são essenciais para o desempenho adequado de todas as funções dos tutores online. Em 90,62\% das instituições analisadas por Oliveira e Lima (2014), esses saberes foram identificados como necessários ao tutor. Mas não correspondem no modelo a funções técnicas, que em geral os tutores não desempenham, como já observamos. E o próprio desenvolvimento dessas competências, na educação a distância, estaria alterando as práticas da educação presencial. 
[...] dada a rápida expansão da $\mathrm{EaD}$, muitos desses saberes e conhecimentos, especialmente os relacionados ao domínio das tecnologias digitais, não fazem parte do perfil profissional exigido inicialmente para a atuação na modalidade. Desse modo, são construídos ao longo da prática pedagógica na EaD, influenciando e transformando o docente em sua atuação, até mesmo na educação presencial, pois muitos atuam concomitantemente em ambas. (CHAQUIME, 2014, p. 38).

Assim, a própria prática do tutor na educação a distância acabaria por desenvolver saberes e conhecimentos que acabam sendo essenciais para sua atuação profissional.

\section{Avaliação das competências}

Cabe, por fim, lembrar da importância de se desenvolver um sistema de rubricas para a avaliação das competências e funções dos tutores online propostas no modelo. Maia (2014), por exemplo, subdivide as competências em conhecimentos, habilidades e atitudes para diferentes atividades, propondo rubricas e métricas para avaliar o tutor em relação a cada uma das competências identificadas, com variações por indicadores que compõem uma lista de verificação (Tabela 5).

Tabela 5 - Rubrica para avaliar as competências dos tutores

\begin{tabular}{|c|c|c|c|c|}
\hline Excelente & Bom & Médio & Insatisfatório & Inexistente \\
\hline 5 & 4 & 3 & 2 & 1 \\
\hline $\begin{array}{c}\text { Muito forte } \\
\text { evidência do } \\
\text { indicador. }\end{array}$ & $\begin{array}{c}\text { Boa evidência do } \\
\text { indicador. }\end{array}$ & $\begin{array}{c}\text { Alguma evidência } \\
\text { do indicador. }\end{array}$ & $\begin{array}{c}\text { Pouca evidência do } \\
\text { indicador. }\end{array}$ & $\begin{array}{c}\text { Nenhuma evidência } \\
\text { do indicador }\end{array}$ \\
\hline
\end{tabular}

Fonte: Maia (2014).

Esses cinco níveis de classificação permitem abarcar com adequação as nuances no desempenho das competências por parte dos tutores.

\section{CONSIDERAÇÕES FINAIS}

Esta pesquisa propôs um quadro teórico com as principais competências e funções dos tutores online, com o objetivo de servir de fundamento para a elaboração de programas de formação de tutores para a educação a distância. Esse quadro se remete de maior valor para políticas educacionais na área se considerarmos que, na pesquisa conduzida por Oliveira e Lima (2014), nenhum coordenador se referiu à importância da formação para a tutoria, e na pesquisa conduzida por Tenório, Teles e Tenório (2016), as competências reputadas como mais importantes pelos tutores pesquisados foram apontadas como aquelas sobre as quais os pesquisados tinham menor domínio. Além disso, a maior parte das competências, dos saberes e das funções propostos no modelo não fazem parte da formação inicial dos tutores online.

Várias das funções descritas neste artigo deixam claro que os tutores realizam um trabalho docente, apesar de o trabalho do tutor, no Brasil, não ser considerado por muitos docência. Melani (2013, p. 118), por exemplo, destaca o fato de os tutores terem indicado que "o tutor é professor, apesar da compreensão de não serem reconhecidos e valorizados institucionalmente como docentes." Mas cabe ressaltar a precarização a que o trabalho da docência online vem sendo submetido na educação a distância no Brasil, o que valoriza ainda mais seu processo de formação. Carvalho (2009, p. 57) avança nessa reflexão, com propostas dos próprios tutores:

[...] alguns entrevistados disseram acreditar que os tutores devem possuir status de professores. A distinção entre eles deveria ser feita da seguinte forma: os atuais professores se chamariam "coordenadores da disciplina" e os tutores, sim, seriam chamados de professores. Mas não se trata apenas de capricho, vaidade. Eles justificam que a atual nomenclatura confere status inferior aos tutores, influenciando na autoridade, no peso de suas palavras, não apenas na relação entre tutores e alunos, mas no relacionamento entre tutores e professores.

Por esta "inferioridade", eles não se sentem à vontade para dialogar horizontalmente, como pares, com os professores sobre as atividades do cotidiano da tutoria. Pelas atribuições dos tutores na EA, eles deveriam ser legitimados como professores, pois é a função que de fato desempenham. 
Uma das limitações desta pesquisa é que a revisão de literatura foi realizada apenas em língua portuguesa. Pesquisas similares incorporando textos em outras línguas poderão contribuir para o enriquecimento do modelo proposto.

Como sugestões para trabalhos futuros, esta pesquisa demonstrou que há mais discussões teóricas do que resultados de pesquisas empíricas em relação às funções dos tutores online, o que justifica projetos na área. No mesmo sentido, em relação às competências, a pesquisa demonstrou que há menos pesquisas sobre as competências comportamentais do que sobre as competências técnicas.

É possível também repensar o modelo proposto levando em consideração o conceito de polidocência em educação a distância (MILL; RIBEIRO; OLIVEIRA, 2010; MILL, 2012), que foi inclusive um código novo incluído na análise de dados, mas que se mostrou presente apenas nas reflexões teóricas, e não nos resultados de pesquisa, exatamente porque é um conceito que pode servir de orientação para as propostas de formação de tutores, concebendo-os como participantes de uma equipe, e não como docentes isolados. A polidocência na $\mathrm{EaD}$ incluiria, assim, o trabalho do tutor, em parceria com outros profissionais, como professores e designers instrucionais.

Nesse sentido, trabalhos futuros podem desenvolver propostas e cursos de formação para aplicar o modelo.

\section{REFERÊNCIAS}

ALMEIDA, N. L. de O.; MARROIG, R.; PINTO, V. R. R. Competências e habilidades do tutor virtual que influenciam na aprendizagem dos alunos. Revista Pensamento Contemporâneo em Administração, v. 8, n. 2, p. 144-166, 2014.

AMARO, R. Mediação pedagógica online: análise das funções do tutor na Universidade Aberta do Brasil. 2012. Dissertação (Mestrado em Educação) - Universidade de Brasília, Brasília, 2012.

ARETIO, L. G. La educación a distancia: de la teoría a la práctica. Barcelona: Ariel, 2002.

BEHAR, P. A. Competências em Educação a Distância. Porto Alegre: Penso, 2013.

BERGE, Z. L. Facilitating computer conferencing: recommendations from the field. Educational Technology, v. 35, p. 22-30, 1995.

BERGE, Z. L. Example case studies in post-secondary, online teaching. In: HART, G.; MASON, J. (ed.). Proceedings of 'The Virtual University?' symposium. Melbourne, Australia, November 21-22, 1996. p. 99-105.

BLANCHETTE, J. P. Register choice: linguistic variation in an on-line classroom. International Journal of Educational Telecommunications, v. 5, n. 2, p. 127-142, 1999.

BONK, C. J.; DENNEN, V. Frameworks for research, design, benchmarks, training, and pedagogy in web-based distance education. In: MOORE, M. G.; ANDERSON, W. G. (ed.). Handbook of distance education. Mahwah, NJ: Lawrence Erlbaum, 2003. p. 331-348.

BORGES JÚNIOR, A. B.; PEREIRA, P. G.; FILGUEIRA, S. S.; MELO, L. R. Um estudo das competências dos tutores de educação a distância na Rede e-Tec Brasil. In: SIED: EnPED-Simpósio Internacional de Educação a Distância e Encontro de Pesquisadores em Educação a Distância, Universidade Federal de São Carlos, 2014.

BORGES, J. P. F.; COELHO JUNIOR, F. A.; FAIAD, C.; ROCHA, N. F. da. Diagnóstico de competências individuais de tutores que atuam na modalidade a distância. Educação e Pesquisa, v. 40, n. 4, p. 935-951, 2014. 
CARVALHO, M. C. dos S. de Competências dos tutores para atuação em programas de educação a distância mediados pela internet: o caso do curso de graduação em administração da EA/UFRGS. 2009. Dissertação (Mestrado em Administração) - Universidade Federal do Rio Grande do Sul, Porto Alegre, 2009. Disponível em: http://www.lume.ufrgs.br/handle/10183/29974. Acesso em: 17 jun. 2020.

CHAQUIME, L. P. A prática pedagógica na educação a distância transformando a docência: uma análise sobre saberes e desenvolvimento profissional de tutores virtuais. 2014. Dissertação (Mestrado em Educação) - Universidade Federal de São Carlos, 2014.

COELHO JUNIOR, F. A.; FAIAD, C.; BORGES, J. P. F.; ROCHA, N. F. da. Mapeamento de competências profissionais de tutores de cursos na modalidade à distância. Estudos e Pesquisas em Psicologia, v. 13, n. 3, p. 878-896, 2013.

COSTA, S. A. F.; SIEWERDT, R.; RAUSCH, R. B. De professor a tutor: reflexões de professores tutores sobre saberes docentes. In: CONGRESSO NACIONAL DE EDUCAÇÃO - EDUCERE, 20., Pontifícia Universidade Católica do Paraná, Curitiba, 2011. p. 7934-7948. Disponível em: http://educere.bruc.com.br/CD2011/pdf/4765_3440.pdf. Acesso em: 17 jun. 2020.

DUARTE, G. P. As funções do tutor online: análise da interatividade tutor/aluno no Projeto Piloto do Curso de Administração de Empresas da Universidade Federal do Piauí. 2008. Dissertação (Mestrado em Gestão da Educação Profissional e Tecnológica) - Universidade de Brasília, Brasília, 2008.

GRÜTZMANN, T. P.; PINO, M. A B. Del. A comunicação e os saberes dos tutores em educação a distância. In: REUNIÃO NACIONAL DA ANPED, 36., Goiânia, 2013.

MAIA, A. M. Proposta de um programa de capacitação por competências para a tutoria a distância: um estudo de caso no curso de Administração/EaD da UFSC. Dissertação (Mestrado em Administração) Universidade Federal de Santa Catarina, 2014.

MAIA, C.; MATTAR, J. $A B C$ da EaD: a educação a distância hoje. São Paulo: Pearson Prentice Hall, 2007.

MELANI, N. de T. D. Z. Tutoria na educação a distância: um estudo sobre a função pedagógica do tutor. 2013. Dissertação (Mestrado em Educação) - Universidade de Brasília, Brasília, 2013.

MENDES, N. T.; SANTOS, N. A. de S.; TENÓRIO, T.; TENÓRIO, A. As competências socioafetivas aceitação e honradez segundo a percepção de tutores a distância. RIED. Revista Iberoamericana de educación a Distancia, v. 18, n. 1, 2015.

MILL, D. R. S. Docência virtual: uma visão crítica. Campinas, SP: Papirus, 2012.

MILL, D R. S.; RIBEIRO, L. R. de C.; OLIVEIRA, M R. G. de (org.). Polidocência na educação a distância: múltiplos enfoques. São Paulo: EdUFSCar, 2010.

MOORE, M.; KEARSLEY, G. Educação a distância: uma visão integrada. São Paulo: Cengage Learning, 2007.

NOBRE, C. V.; MELO, K. S. de. Convergência das competências essenciais do mediador pedagógico da EaD. In: ESUD - Congresso Brasileiro de Ensino Superior a Distância, 8., Ouro Preto, 2011.

NÓVOA, A. O passado e o presente dos professores. In: NÓVOA, A. (org.). Profissão professor. Portugal: Porto Editora, 1995. p. 13-34.

OKOLI, C. A guide to conducting a standalone systematic literature review. Communications of the Association for Information Systems, v. 37, n. 1, paper 43, p. 879-910, 2015. 
OLIVEIRA, C. L. A. P. Afetividade, aprendizagem e tutoria online. Revista Edapeci, v. 3, n. 3, 2009.

OLIVEIRA, E. da S. G. de; SANTOS, L. Tutoria em Educação a Distância: didática e competências do novo “fazer pedagógico". Revista Diálogo Educacional, v. 13, n. 38, p. 203-223, 2017.

OLIVEIRA, F. P. M. de; LIMA, C. M. de Tutoria e docência nos cursos de Pedagogia da UAB na perspectiva dos saberes docentes. In: SIED: EnPED-Simpósio Internacional de Educação a Distância e Encontro de Pesquisadores em Educação a Distância, 15-26 set., UFSCar, São Carlos, 2014.

PALLOFF, R. M.; PRATT, K. Construindo comunidades de aprendizagem no ciberespaço: estratégias eficientes para a sala de aula on-line. Porto Alegre: Artmed, 2002.

PALLOFF, R. M.; PRATT, K. O aluno virtual: um guia para trabalhar com estudantes on-line. Porto Alegre: Artmed, 2004.

PERRENOUD, P. Dez novas competências para ensinar. Porto Alegre: Artmed, 2000.

PRENSKY, M. Digital natives, digital immigrants. On the horizon, v. 9, n. 5, p. 1-6, 2001.

PRENSKY, M. From digital natives to digital wisdom: hopeful essays for 21 st century learning. Thousand Oaks, CA: Corwin, 2012.

SALDAÑA, Johnny. The coding manual for qualitative researchers. 3rd ed. Los Angeles: Sage, 2016.

SANTOS, M. das G. F. Competências socioafetivas na visão dos tutores e seus desafios. Unisanta Humanitas, v. 5, n. 1, p. 105-120, 2016.

SCHNEIDER, D. MP-CompEAD: modelo pedagógico baseado em competências para professores e para tutores em educação a distância. Tese (Doutorado em Educação) - Universidade Federal do Rio Grande do Sul, Porto Alegre, 2014.

SHULMAN, L. Knowledge and teaching: foundations of the new reform. Harvard Educational Review, v. 57, n. 1, p. 1-23, 1987.

TARDIF, M. Saberes docentes e formação profissional. 17. ed. Petrópolis, RJ: Vozes, 2010.

TECCHIO, E. L.; NUNES, T. S.; MORETTTO, S. M.; DALMAU, M. B.; Melo, P. A. Competências fundamentais ao tutor de ensino a distância.Colabor@_Revista Digital da CVA-RICESU, v. 6, n. 21, 2010.

TELES, L. F. A aprendizagem por e-learning. In: LITTO, F. M.; FORMIGA, M. M. (ed.). Educação a distância: o estado da arte. São Paulo: Pearson Education do Brasil, 2009. p. 72-80.

TENÓRIO, A.; ALMEIDA, A. C. C. de; TENÓRIO, T. Percepções de tutores sobre a influência de competências pedagógicas no ensino aprendizagem a distância. Revista EducaOnline, v. 9, n. 3, p. 107124, 2015.

TENÓRIO, A.; BEZERRA, C. K. B.; TENÓRIO, T. Competências gerenciais do tutor na educação a distância.Paidéi@: Revisa Científica de Educação a Distância, v. 7, n. 12, p. 1-19, 2015.

TENÓRIO, A.; GAMA, C. O. da; TENÓRIO, T. Percepções de tutores sobre as competências comportamentais. EaD em FOCO, v. 5, n. 3, p. 142-169, 2015. 
TENÓRIO, A.; LOOS, T.; TENÓRIO, T. Perceptions of tutors and students on affectivity and conflict mediation in an e learning course for the Brazilian police. RIED. Revista Iberoamericana de Educación a Distancia, v. 20, n. 1, p. 223-241, 2017.

TENÓRIO, A.; PIRES, D. N.; TENÓRIO, T. A influência de competências socioafetivas no processo de ensino-aprendizagem com base nas percepções de tutores a distância. Paidéi@: Revista Cientifica de Educação a Distância, v. 9, n. 15, p. 1-18, 2017.

TENÓRIO, A.; SOUTO, E. V. de; TENÓRIO, T. Percepções sobre a competência socioafetiva de cordialidade e a humanização da tutoria a distância. EaD em FOCO, v. 4, n. 1, p. 36-47, 2014.

TENÓRIO, A.; TELES, A. dos S.; TENÓRIO, T. Levantamento de competências pedagógicas necessárias a tutores da educação a distância. RIED. Revista Iberoamericana de Educación a Distancia, v. 19, n. 1, p. 183-207, 2016.

Submetido: 07/12/2018

Aprovado: $19 / 04 / 2020$

DOI: http://dx.doi.org/10.1590/0102-4698012020

\section{ERRATA}

\section{No artigo:}

MATTAR, JOÃO et al . COMPETÊNCIAS E FUNÇÕES DOS TUTORES ONLINE EM EDUCAÇÃO A

DISTÂNCIA. Educ. rev., Belo Horizonte, v. 36, e217439, 2020. Disponível em

<http://www.scielo.br/scielo.php?script=sci_arttext\&pid=S0102-46982020000100222\&lng=pt\&nrm=iso >. acessos em 24 jul. 2020. Epub 06-Jul-2020. https://doi.org/10.1590/0102-4698217439.

Na nota de rodapé 2, relativa à afiliação do autor,

Onde se lê:

Centro Universitário Internacional Uninter. Faculdade FAEL. Curitiba, PR, Brasil. lucilenemmrodrigues@gmail.com

\section{Leia-se:}

Centro Universitário Internacional Uninter. FAE Centro Universitário. Curitiba, PR, Brasil. lucilenemmrodrigues@gmail.com 